\title{
Geoffroy's side-necked turtle [Phrynops geoffroanus (Schweigger, 1812), Testudines: Chelidae] as a model for evolutionary ecotoxicology: relationship between environmental contamination, conditions and genetic variability
}

\author{
L.P.R. Venancio, D.A.P.C. Zuccari and C.R. Bonini-Domingos
}

2012. Pós-Graduação em Genética, Instituto de Biociências, Letras e Ciências Exatas, Universidade Estadual Paulista “Júlio de Mesquita Filho", São José do Rio Preto, SP, Brasil

$\mathrm{PhD}$ thesis. Orienting Prof.: C.R. Bonini-Domingos, Co-orienting Prof.: D.A.P.C. Zuccari

DOI http://dx.doi.org/10.4238/2013.December.19.4

Corresponding author: L.P.R. Venancio

E-mail: larissa_biorp@yahoo.com.br

The objective of this study was to evaluate the role of human activity factors, such as environmental contamination and habitat changes, as drivers for changing the physiological, biochemical, and genetic diversity of Geoffroy's side-necked turtle populations in one of the most impacted watersheds in southeastern Brazil. The impact of chemical and organic contamination was determined by ecotoxicological analyses to assess the action of some of the major components involved in protection against oxidative stress, phase I and II detoxification metabolism, and antioxidant capacity. The results indicated the influence of domestic and industrial effluents on detoxification metabolism and oxidative stress. However, in spite of increased activity and effect of EROD (CYP1A1) and glutathione $S$-transferase (GST) activity, GST average values in the urban area agreed with those expected for hypoxic conditions according to the literature. This observation suggests that increased GST in response to ROS production due to the presence of pollutants increases the antioxidant defense network, con- 
trolling the oxidative damage caused by hypoxia and reperfusion. To determine the conditions that are reflected in individual ability (fitness), we evaluated the mathematical relationship between weight and length, and found that changes in body shape and weight increase, allowing inferences about animal health and welfare. The data obtained indicate differences in conditions that are associated with the area, but also with sex and reproductive period, and contamination gradient, indicating a strong influence of environmental stressors on the physiology of the specimens. The evaluation of genetic structure among populations of Preto River and Felicidade Stream, based on microsatellites, demonstrated that there was no genetic differentiation, due to extensive gene flow between the areas and high genetic diversity. However, after analysis of intrapopulation structure, we observed the existence of five genetic groups that reflected changes in habitat created by damming and siltation, which initiate separation processes (barriers) between sub-populations. The relationship between the data obtained for biochemical parameters, condition factors and genetic diversity was analyzed by heterozygosity-fitness correlation. The negative relationship observed may be explained by the profile of structural and ecological changes in the populations studied, indicating the important influence of humans on the biology of natural populations. Therefore, Phrynops geoffroanus shows adaptation to environmental contamination, and ecological changes and possible loss of habitat are altering the genetic diversity of the populations studied. This is the first study evaluating all these aspects of $P$. geoffroanus simultaneously in natural populations in Brazil, using this species as a model.

Key words: Phrynops geoffroanus; Ecotoxicology; Condition factor; Population genetics; Heterozygosity-fitness correlation; Environmental changes

\section{ACKNOWLEDGMENTS}

Research supported by Conselho Nacional de Desenvolvimento Científico e Tecnológico (CNPq; Processo \#143419/2008-0). Thanks are due to Prof. Dr. Alexandre Rodrigues

Caetano, Prof. Dr. Samuel Rezende Paiva, Dr. Patrícia Ianella (Embrapa/Cenargen), and Prof. Dr. Eduardo Alves de Almeida (UNESP/Ibilce). 